\title{
PHYSIOTHERAPY - THE WORM'S EYE VIEW
}

\author{
By J. B. ODAMS
}

$\mathbf{M}^{\mathrm{Y}}$ $Y$ title is not meant to imply that in the hands of a physiotherapist the patient feels like something that "crawled from under a stone", but rather that the writer is, and has been, a patient undergoing physiotherapy. Eighteen months ago I married a physiotherapist, and six months ago I was attacked by polio, and so I am no new convert to the creed; and yet, what can any enthusiastic amateur hope to be able to tell the professional physiotherapist about her occupation - probably nothing that she has not heard before. I thought, however, that it might be useful to talk about the psychological approach of the physiotherapist to her patient, and the effect each type of approach has on the patient. I have no doubt that this subject crops up more than patie in the physiotherapist's training and it might be useful If my own experiences bear out what is taught during that training. I realise, of course, that the physiotherapist's approach must depend upon the age and the mental equipment of the patient whom she is attending. I have seen a great deal of success gained with children between the ages of two and six when the physiotherapist makes of their exercises a game; they are to be a train. The legs open wide like the carriage doors and all the people get in; the legs then start pumping slowly and the train pulls away from the platform; faster and faster it goes until it reaches the next station where the same performance is repeated, as the people get out and the doors close and the train moves on to its destination. I have also heard experienced physiotherapists who claim that children must be treated in an adult fashion, must be made to realise that the exercises that they are doing are serious, and any element of play that is introduced is nothing more than a relaxation. I do not, however, wish to discuss or criticise such points as these, for I feel that the only value that this article can have comes from its subjective approach, its account of my own experiences.

Now I am very glad to say that I have never been bullied, but I am told that there are cases where the patient has, perhaps, given up hope and where it is psychologically necessary that they be bullied before any work at all can be extracted from them. May I be bold enough to suggest that this should be a last resort for the physiotherapist. The immediate result which it would have on me - speaking Sersonally - is to make me "dig my toes in" metaphorically, And become extremely obstinate. It is a rather unfortunate fact that a patient, after some time in hospital, acquires a morbid enthusiasm for, and interest in his own symptoms and weaknesses. The physiotherapist has my co-operation who makes capital out of this human failing. If she explains precisely what muscle is making what movement and what each movement is designed to exercise, she immediately has me contemplating my own body, a thing which I have been doing for some weeks already while lying in bed. This, then, is my main thesis. Given a patient of average mental ability over the age of six, co-operation can be coaxed from him, even against his own will, in this way.

When will this co-operation wear thin? In a patient with only slight paralysis, or paresis he will be cured before his enthusiasm has waned; but if paralysis of one type or another has a firm grip, the patient's co-operation and interest may begin to wane after same weeks, when miraculous improvements which he had expected are not forthcoming. There seems to come now a period between the early enthusiasm and final realisation and resignment to a long, slow recuperation, a rather hopeless time when, as far as the patient can see, nothing is doing him any good. During this middle period three things especially helped me. First of all my attention was constantly being drawn by the physiotherapist to all the small new achievements, which in that state of mind would probably have gone unnoticed. Also, it was constantly impressed upon me how slow a polio affected muscle is to improve, until the idea finally settled with me and became part of my make-up. And finally, an elementary point perhaps, my exercises were changed at that stage and it was surprising how this stimulated my interest. Some of the changes were co-incidental, others were contrived by the physiotherapist; some were made possible through my emergence from the iron lung on to a bed; others were different exercises which moved the same muscles as had been worked for the past twelve weeks; but this semblance of a change was much better than a rest.

And now there is quite an adventure ahead until I can start working again; an adventure involving a new car with hand controls, the choosing of a wheel chair, the building of a Guthrie-Smith bed frame for our home, and many other things which will assure my continued interest and cooperation with the physiotherapist, even if she is my wife.

\section{MISSING PERSONS}

Miss Frere, formerly of Jane Furze Hospital.

Mrs. Kelfkens, formerly of Roodepoort, Transvaal.

Mrs. Kitson, formerly of Johannesburg.

\section{Deliverance}

from pain ... the humanitarian function of of the practitioner... now accomplished with greater speed, more economy and with a higher degree of safety than ever before.

Full details and clinical notes on the use of

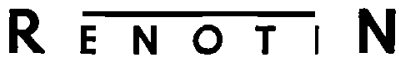

in the treatment of Migraine, Neuritis, Lumbago, Sprains and Myalgia may be obtained from

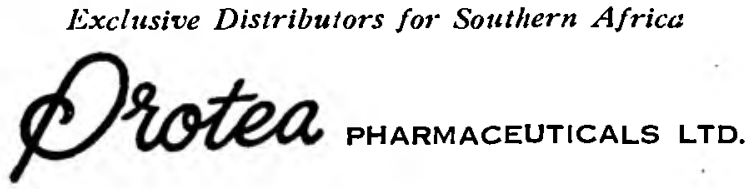

P.O. BOX 7793 JOHANNESBURG 